\title{
IbM SISTEM BANK SAMPAH SEBAGAI SOLUSI PENANGANAN SAMPAH DI DESA BERBEK KECAMATAN WARU KABUPATEN SIDOARJO
}

\author{
Sri Widyastuti ${ }^{1)}$ Joko Sutrisno ${ }^{2)}$ Setyo Purwoto ${ }^{3)}$ Pungut $^{4)}$ \\ 1,2,3,4 Program Studi Teknik Lingkungan Fakultas Teknik Sipil dan Perencanaan DI DESA \\ Email : ${ }^{1}$ sriwidyastuti@unipasby.ac.id, ${ }^{2}$ jsutrisno.adibuana@yahoo.com, ${ }^{3}$ setyopurwoto.enviro@gmail.com, \\ ㄹungutasmoro@unipasby.ac.id
}

\begin{abstract}
Abstrak
Telah dilakukan pengabdian masyarakat di Desa Berbek Kecamatan Waru Kabupaten Sidoarjo Propinsi Jawa Timur. Adapun tujuan kegiatan pengabdian ini adalah perubahan pola pikir masyarakat untuk mengelola sampah kering (anorganik) dengan menerapkan Sistem Bank Sampah sebagai Solusi Penanganan Sampah Kering (anorganik) di Desa Berbek Kecamatan Waru Kabupaten Sidoarjo. Metoda pelaksanaan pengabdian masyarakat adalah (1) pemberian pre test Bank Sampah, (2) pemberian Materi Teori dengan judul Mengubah Pola Pikir Pengelolaan Sampah dengan Sistem Bank Sampah, (3) praktek Pengelolaan Bank sampah, (4) post test berkaitan dengan materi yang telah di berikan, (5) pendampingan selama proses berjalan nya Bank Sampah Berdasarkan hasil kegiatan pengabdian masyarakat ini warga mau melaksanakan pemilahan sampah dan menyetorkan sampah kering (anorganik) ke Bank Sampah di Desa Berbek Kecamatan Waru Kabupaten Sidoarjo yang di beri nama Bank Sampah Berbek Mandiri. Bank Sampah ini membuat warga masyarakat ikut andil dalam bagian menjaga lingkungan,menjaga kebersihan lingkungan dan presepsi masyarakat tentang sampah yang tidak punya nilai guna kini berkurang.
\end{abstract}

Kata kunci : Pengelolaan sampah, Bank sampah, Berbek waru

\begin{abstract}
Community service has been carried out in Berbek Village, Waru District, Sidoarjo Regency, East Java Province. The purpose of this community service activity is to change the mindset of the community to manage dry (inorganic) waste by implementing the Trash Bank System as a Solution for Handling Dry Waste (inorganic) in Berbek Village, Waru District, Sidoarjo Regency. The methods of implementing community service are (1) providing pre-test trash Bank, (2) providing Theory Material with the title Changing the Mindset of Waste Management with the Waste Bank System, (3) the practice of Waste Bank Management, (4) post test related to the material that has been given, (5) assistance during the process of the Trash Bank. Based on the results of this community service activity, the residents want to carry out waste sorting and deposit dry rubbish (inorganic) to the Trash Bank in Berbek Village, Waru Subdistrict, Sidoarjo Regency, which is named the Mandiri Trash Bank. This Garbage Bank makes the community members take part in protecting the environment, maintaining environmental cleanliness and public perception of waste that has no use value is now reduced.
\end{abstract}

Key Words : Waste manangement, Trash bank, Berbek waru 


\section{PENDAHULUAN}

Paradigma pengelolaan sampah saat ini adalah pemilahan dari sumber, yang meliputi 4R yaitu reduce, reuse, recycle, recovery, komposting. Reduksi sampah di sumber dilakukan agar residu yang dibuang ke Tempat Pemrosesan Akhir (TPA) Sampah menjadi lebih sedikit. Keterbatasan lahan TPA Sampah juga menjadi permasalahan baru yang sering dihadapi oleh kota besar (Kementerian PUPR, 2016). Peran serta masyarakat menjadi peranan utama dalam melakukan pengelolaan sampah di sumbernya. Seluruh lapisan masyarakat harus turut serta membantu pemerintah untuk bergerak bersama dalam menangani permasalahan sampah. Salah satunya pengelolaan sampah anorganik atau sampah kering adalah dengan penerapan prinsip $3 \mathrm{R}$ (reduce, reuse, recycle) dalam wujud Bank Sampah (Peraturan Menteri PU Nomor 21 Tahun 2006) ..

Desa Berbek Kecamatan Waru Kabupaten Sidoarjo mayoritas penduduknya bermata pencaharian sebagai petani dan pedagang. Total penduduk Desa Berbek berjumlah 3.570 jiwa yang terdiri dari lakilaki sebanyak 1.821 jiwa dan perempuan berjumlah 1.749 jiwa dengan dengan luas wilayah 972,4 $\mathrm{km}^{2}$. Potensi desa yang dimiliki oleh Desa Berbek adalah berupa sawah-sawah ( Data Desa Berbek waru Sidoarjo) .

Kegiatan rumah tangga menghasilkan limbah padat yang berupa sampah organik maupun anorganik. Permasalahan yang muncul di Desa Berbek Kecamatan Waru Kabupaten Sidoarjo adalah masyarakat belum melaksanakan pengelolaan sampah dengan baik. Sampah dibuang begitu saja ke Tempat Pemrosesan Akhir (TPA) Sampah ataupun dibakar. Berdasarkan Undangundang No. 18 Tahun 2008 tentang
Pengelolaan Sampah diyatakan bahwa sampah harus di kurang dan dipilah sejak di sumber.

Sehingga tujuan kegiatan pengabdian ini adalah perubahan pola pikir masyarakat untuk menerapkan Sistem Bank Sampah sebagai Solusi Penanganan Sampah Kering (Anorganik) di Desa Berbek Kecamatan Waru Kabupaten Sidoarjo.

Secara garis besar permasalahan yang ada di Desa Berbek Kecamatan Waru Kabupaten Sidoarjo adalah:

1. Warga masyarakat yang belum melakukan pemilahan sampah anorganik di sumber.

2. Warga masyarakat yang belum mengerti cara penanganan sampah anorganik dengan sistem bank sampah.

3. Masyarakatnya belum memahami tentang potensi ekonomi atau nilai guna barang yang dihasilkan dari sampah.

4. Masyarakatnya belum memahami pelaksanaan bank sampah untuk penanganan sampah anorganik.

5. Perlu adanya usaha tentang penanganan sampah anorganik.

\section{KAJIAN LITERATUR}

Bank sampah lahir dari program Jakarta Green and Clean yaitu salah satu cara pengelolaan sampah skala rumah tangga, yang menitik beratkan pada pemberdayaan masyarakat dalam mengelola sampah rumah tangga. Bank sampah adalah tempat menabung sampah yang telah terpilih menurut jenis sampah, sampah yang ditabung pada bank sampah adalah sampah yang mempunyai nilai ekonomis (Wahdah, N. F.,et all, 2019) . Cara kerja bank sampah pada umumnya hampir sama dengan bank lainnya, ada nasabah, pencatatan pembukuan dan manajemen pengelolaannya, apabila dalam bank yang biasa kita kenal yang disetorkan 
nasabah adalah uang akan tetapi dalam bank sampah yang disetorkan adalah sampah yang mempunyai nilai ekonomis, sedangkan pengelola bank sampah harus orang kreatif dan inovatif serta memiliki jiwa kewirausahaan agar dapat meningkatkan pendapatan masyarakat (Asteria, D., \& Heruman, H., 2016)..

Sistem kerja bank sampah sebagai pengelolaan sampahnya berbasis rumah tangga,adalah dengan memberikan reward kepada yang berhasil memilah dan menyetorkan sejumlah sampah (Unilever Green and Clean, 2010). Bank sampah menjadi metode alternatif pengelolaan sampah yang efektif, aman, sehat dan ramah lingkungan. Hal ini dikarenakan pada bank sampah, masyarakat menabung dalam bentuk sampah yang sudah dikelompokkan sesuai jenisnya sehingga dapat memudahkan pengelolaan bank sampah dalam melakukan pengelolaan sampah seperti pemilahan dan pemisahan sampah berdasarkan jenisnya sehingga tidak terjadi pencampuran antara sampah organik dan non organik yang membuat bank sampah lebih efektif, aman, sehat dan ramah lingkungan (Unilever Green and Clean, 2010).

Konsep bank sampah ini tidak jauh berbeda dengan konsep 3R (Reduse, Reuse, Recycle). Jika dalam konsep 3R ditekankan bagaimana agar mengurangi jumlah sampah yang ditimbulkan dengan menggunakan atau mendaur ulangnya, dalam konsep bank sampah ini, paling ditekankan adalah bagaimana agar sampah yang sudah dianggap tidak berguna dan tidak memiliki manfaat dapat memberikan manfaat tersendiri dalam bentuk uang, sehingga masyarakat termotivasi untuk memilah sampah yang dihasilkan. Proses pemilahan inilah yang mengurangi jumlah timbunan sampah yang dihasilkan dari rumah tangga sebagai penghasil sampah terbesar di perkotaan.
Konsep Bank Sampah membuat masyarakat sadar bahwa sampah memiliki nilai jual yang dapat menghasilkan uang, sehingga mereka peduli untuk mengelolanya, mulai dari pemilahan, pengomposan, hingga menjadikan sampah sebagai barang yang bisa digunakan kembali dan bernilai ekonomis (Aryenti, 2011).

Konsep bank sampah ini menjadi salah satu solusi bagi pengelolaan sampah di Indonesia yang masih bertumpu pada pendekatan akhir. Dengan program ini, sampah mulai dikelola dari awal sumber timbunan sampah, yaitu rumah tangga. Pemilihan yang dilakukan oleh masyarakat sejak awal membuat timbunan sampah yang dihasilkan dan dibawa ke tempat pembuangan akhir (TPA) menjadi berkurang (Medan Green and Clean, 2010). Keberadaan bank sampah mampu memberikan nilai ekonomis bagi warga masyarakat. Sistem ini berfungsi mengelola sampah dengan menampung, memilah, dan mendistribusikan sampah ke fasilitas pengolahan sampah yang lain atau kepada pihak yang membutuhkan. Sistem pengelolaan sampah kering ini secara kolektif mendorong masyarakat untuk berperan serta aktif didalamnya.

Dengan demikian, adanya bank sampah dapat mengurangi sampah yang dibuang di TPA, menambah nilai guna barang yang sebelumnya dianggap tak berguna, dan dapat meningkatkan perekonomian masyarakat karena mendapat keuntungan ekonomi dari menabung sampah. Semua kegiatan dalam sistem Bank Sampah dilakukan dari, oleh, dan untuk masyarakat. Seperti halnya bank konvensional, Bank Sampah juga memiliki sistem manajerial dan operasional yang dilakukan oleh masyarakat. Adapun tahapan pendirian dan pengembangan sistem Bank Sampah adalah sosialisasi awal, pelatihan teknik, 
pelaksanaan sistem bank sampah, pemantauan dan evaluasi, pengembangan.

\section{METODE PELAKSANAAN}

Rancangan kegiatan sebagai solusi yang ditawarkan dalam kegiatan program PPM ini adalah dengan melakukan penyuluhan tentang mengubah pola pikir masyarakat dalam pengelolaan sampah dan melakukan praktik teknis dalam rangka pendirian dan pengembangan sistem bank sampah hingga ke pendampingan kepada pengurus Bank Sampah. Partisipasi masyarakat tentunya dibutuhkan demi kelancaran kegiatan tersebut.

Gambaran teknologi yang akan diterapkan untuk menyelesaikan masalah sebagai ruang lingkup atau objek yaitu sistem bank sampah dalam penanganan sampah anorganik yang ada di Desa Berbek Kecamatan Waru Kabupaten Sidoarjo.

Teknik pengumpulan data yang dilakukan

1. Pemberian pre test materi tentang sisitem pengelolaan sampah kering (anorganik) dengan menggunakan Bank Sampah

2. Pemberian Materi Teori dengan judul Mengubah pola pikir pengelolaan sampah dengan Sistem Bank Sampah

3. Praktek Pengelolaan Bank sampah

4. Post Test berkaitan dengan materi yang telah di berikan

5. Pendampingan selama proses berjalan nya Bank Sampah

Mitra dalam pelaksanaan kegiatan PPM ini adalah:

a. Pemerintah Desa Berbek

b. Kelompok PKK

c. Kelompok Karang Taruna

\section{HASIL DAN PEMBAHASAN}

Kementerian Lingkungan Hidup dan Kehutanan (KLHK) bertekad mengurangi jumlah sampah nasional melalui program bank sampah. Perkembangan program bank sampah di seluruh Indonesia meningkat dalam kurun waktu tiga tahun terakhir. Pada tahun 2015, jumlah bank sampah di Indonesia sebanyak 1.172 unit dan tahun 2017 jumlah bank sampah di Indonesia mencapai 5.244 unit yang tersebar di 34 provinsi dan 219 kabupaten/kota di Indonesia.

Program bank sampah adalah program yang mengajak masyarakat untuk memilah sampah organik dan non-organik untuk ditukarkan menggunakan uang pada bankbank sampah yang telah tersebar di 34 provinsi di Indonesia. Namun, ada juga bank sampah yang menerapkan penukaran sampah untuk pembayaran listrik, pembelian sembako, pembayaran biaya kesehatan, dan mendapatkan emas. Program bank sampah itu bisa mengubah paradigma masyarakat untuk memaknai sampah sebagai sesuatu yang mempunyai nilai untuk dimanfaatkan kembali sekaligus mengurangi jumlah sampah nasional

Pada bank sampah, sampah organik akan didaur ulang menjadi kompos. Sementara sampah non-organik akan diolah kembali agar bisa bermanfaat secara ekonomis.

Berbagai sampah anorganik yang dihasilkan oleh warga Desa Berbek antara lain botol plastik, kertas, kardus, kantong plastik. Sampah anorganik ini akan disetorkan ke Bank Sampah Berbek Mandiri. Proses pemilahannya berdasarkan jenis-jenis sampah. Untuk botol yang berwarna putih memliki nilai jual paling tinggi karena lebih mudah untuk proses pewarnaan kembali dalam proses pendauran ulang. Botol kaca seperti bekas sirup dikumpulkan dan dikirim ke PT. Kedawung yang merupakan perusahaan pengelola barang kaca. Kemudian kertas juga dipisah berdasarkan ketebalan dan bahannya. Warga juga 
mengumpulkan jelantah yang akan dikumpulkan pada jirigen dan dikirim ke pabrik sebagai feed material biodiesel. Adapun Foto hasil kegiatan adalah sebagai berikut

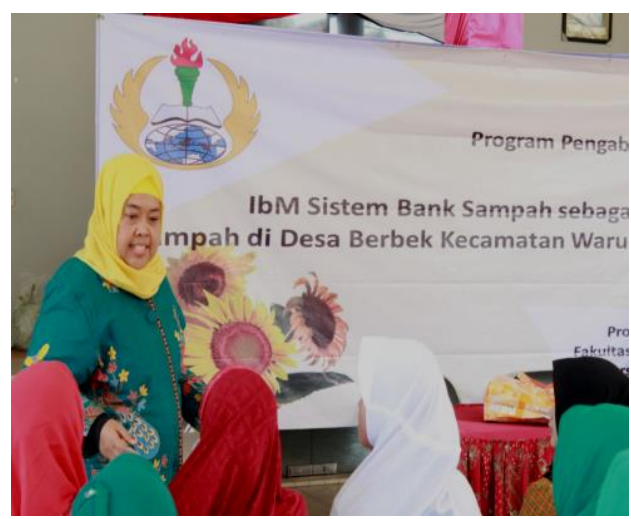

Gambar 1. Pelaksanaan Post Tes

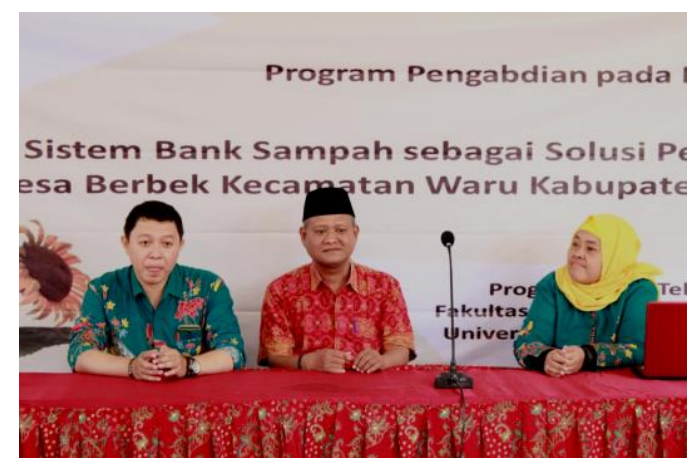

Gambar 2. Pembukaan acara Pengabdian oleh Kaprodi dan Bapak Kepala Desa Berbek

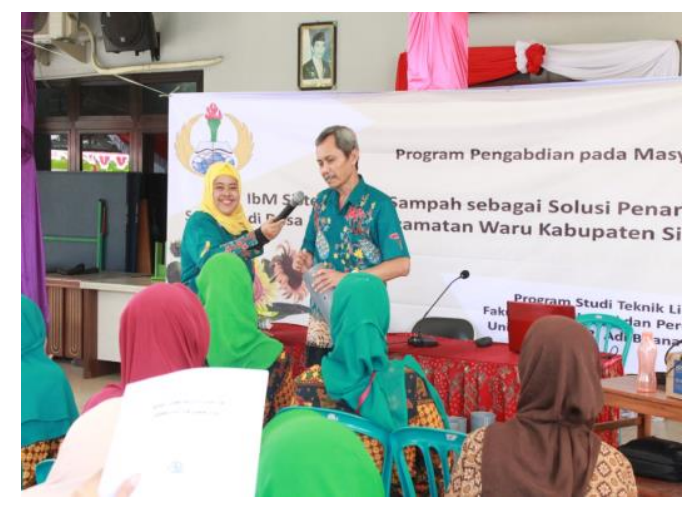

Gambar 3. Pemberian Materi

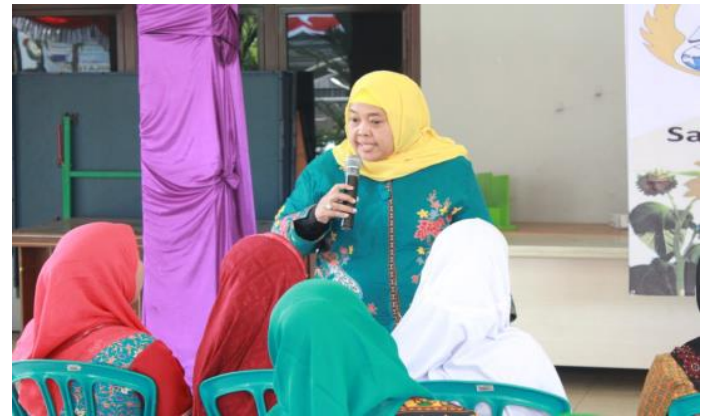

Gambar 4. Tanya jawab sistem bank sampah yang paling memungkinkan untuk di lakukan

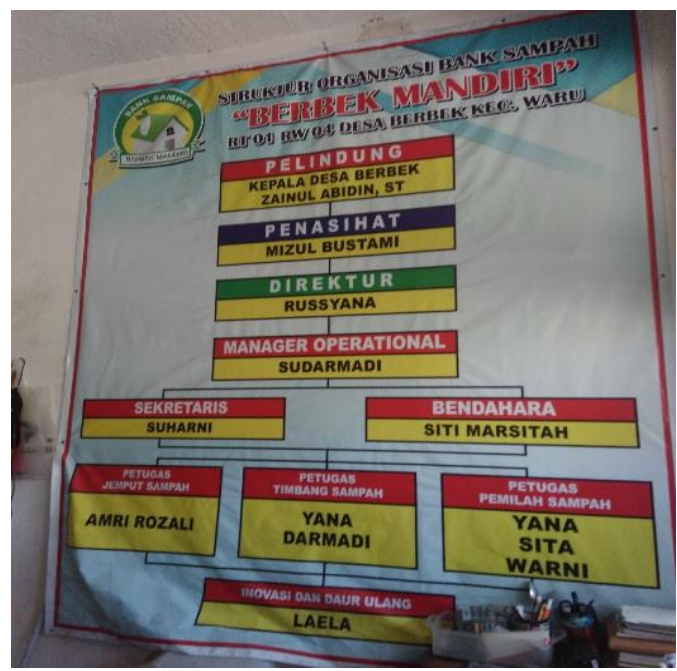

Gambar 5. Pembentukaan dan Pembuatan Struktur Organisasi Bank Sampah Berbek Mandiri

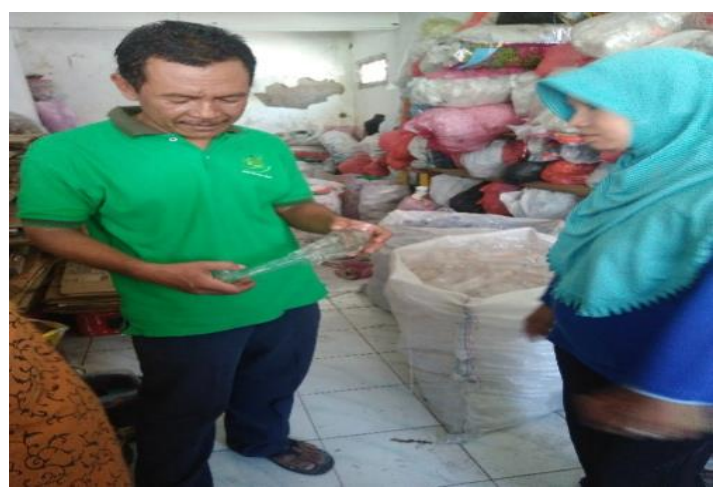

Gambar 6. Pendampingan Ke Gudang Bank sampah 


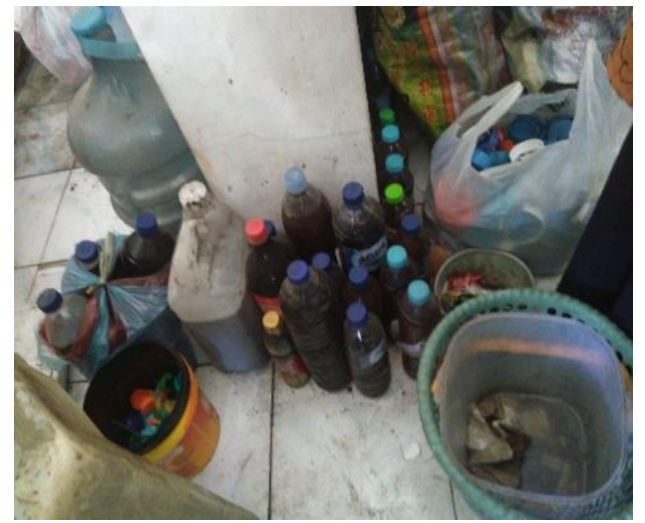

Gambar 7. Kunjungan dan Pendampingan untuk Pengelolaan Minyak Jelantah

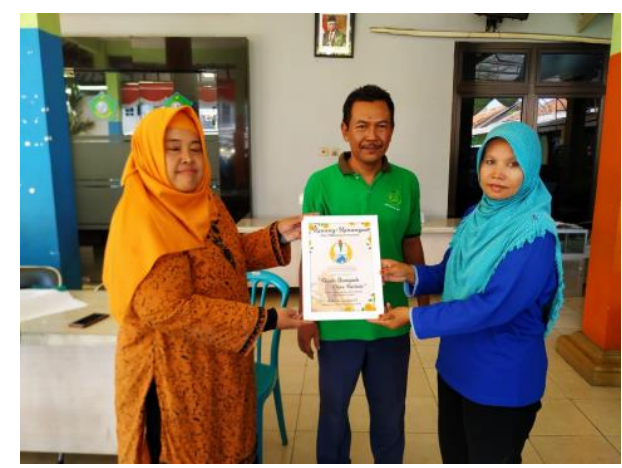

Gambar 8. Pendampingan dan pemberian Kenang kenang berupa buku bank sampah

Pengelolaan sampah dengan sistem bank sampah yang bersifat kolektif dan sistematis memiliki dampak positif bagi masyarakat, lingkungan dan memiliki nilai ekonomis.

Dalam sistem bank sampah yang di tabung adalah sampah anorganik, karena sampah anorganik ini proses penguraiannya membutuhkan waktu yang cukup lama, sumber banyaknya sampah anorganik salah satu nya adalah sampah rumah tangga. Jumlah penduduk indonesia No.2 terbanyak di dunia setelah China (Sarfiah, S. N., \& Juliprijanto, W. 2019).Sampah domestik ini menjadikan permasalahan yang rumit untuk indonesia apalagi daerah perkotaan memiliki pabrik-pabrik industri yang sangat berpotensi membawa dampak buruk bagi ekologi lingkungan . salah satu cara inilah bank sampah membuat rekomendasi untuk warga agar setiap warga negara indonesia ini turut menjaga lingkungan tidak hanya menitikberatkan persoalan sampah ini kepada pemerintah kita pun wajib sebagai warga negara yang mempunyai hak dan kewajiban di negara ini, setidaknya kita dapat mengurangi sampah di indonesia walaupun tidak bisa menghilangkannya.

\section{KESIMPULAN}

Berdasarkan hasil kegiatan pengabdian masyarakat ini warga mau melaksanakan pemilahan sampah dan menyetorkan sampah kering (anorganik) ke Bank Sampah di Desa Berbek Kecamatan Waru Kabupaten Sidoarjo yang di beri nama Bank Sampah Berbek Mandiri

Bank Sampah ini membuat warga masyarakat dalam suatu tempat tersebut ikut andil dalam bagian menjaga lingkungan,menjaga kebersihan lingkungan dan presepsi masyarakat tentang sampah yang tidak punya nilai guna kini berkurang

\section{REFERENSI}

Aryenti, 2011. Peran Pendamping Masyarakat Dalam Pengelolaan Sampah 3R Di Kota Banjar. Jurnal Permukiman. Vol 7 No. 1 April 2012. Pusat Litbang Permukiman, Kementerian PU, Bandung.

Asteria, D., \& Heruman, H. (2016). Bank Sampah Sebagai Alternatif Strategi Pengelolaan Sampah Berbasisi Masyrakat Di Tasikmalaya. Jurnal Manusia dan Lingkungan, 136-141.

Peraturan Menteri PU Nomor 21 Tahun 2006. tentang Kebijakan dan Strategi Nasional Pengembangan Sistem Pengelolaan Persampahan. Jakarta Kementerian PUPR, 2016 , Indonesia Bebas Sampah 2020, 
http://ciptakarya.pu.go.id/dok/bulleti n/bulletinCK_feb16.pdf

Sarfiah, S. N., \& Juliprijanto, W. (2019). Manfaat Bank Sampah Bagi Masyarakat Disusun Semali Desa Salamkanci Kecamatan Bandongan Kabupaten Magelang (Study Bank Sampah Semali Berseri). 165--184.

Wahdah, N. F., Kusnia, Faisal, H. A., Istna Ainur Rohmah, A. A., Herfianto, Muharaini, N. K., Abdillah, R. B. (2019).

Bank Sampah Sebagai Sarana Peningkatan Ekonomi Kreatif dan Kesadaran Lingkungan. Prosiding Konferensi pengabdian Masyarakat, 505-506.

Yuliana, I., \& Wijayanti, Y. (2019). Partisipasi Masyarakat Pada Program Bank Sampah. Higeia Journal Of Public Health Research And Development, 545555.

Undang-Undang RI No. 18, 2008, Pengelolaan Sampah. Jakarta

2010. Unilever Green and Clean "Bumi Kita”. Yayasan Unilever Indonesia. Jakarta , 2010. Bank Sampah dan Program Lingkungan Yayasan Unilever. http// www.unilevergreenandclean.co.id/gr eenandclean. Yayasan Unilever Indonesia. Diakses pada tanggal 23 Januari 2012,

2010. Koperasi Bank Sampah, Solusi Permasalahan Sampah Yang Menguntungkan. http// www.unilevergreenandclean.co.id/gr eenandclean/banksampah. Yayasan Unilever Indonesia.

Asteria, D., \& Heruman, H. (2016). Bank Sampah Sebagai Alternatif Strategi Pengelolaan Sampah Berbasisi Masyrakat Di Tasikmalaya. Jurnal Manusia dan Lingkungan, 136-141.
Peraturan Menteri PU Nomor 21 Tahun 2006. tentang Kebijakan dan Strategi Nasional Pengembangan Sistem Pengelolaan Persampahan. Jakarta

Kementerian PUPR, 2016, Indonesia Bebas Sampah 2020, http://ciptakarya.pu.go.id/dok/bulleti n/bulletinCK_feb16.pdf

Sarfiah, S. N., \& Juliprijanto, W. (2019). Manfaat Bank Sampah Bagi Masyarakat Disusun Semali Desa Salamkanci Kecamatan Bandongan Kabupaten Magelang (Study Bank Sampah Semali Berseri). 165--184.

Wahdah, N. F., Kusnia, Faisal, H. A., Istna Ainur Rohmah, A. A., Herfianto, Muharaini, N. K., Abdillah, R. B. (2019).

Bank Sampah Sebagai Sarana Peningkatan Ekonomi Kreatif dan Kesadaran Lingkungan. Prosiding Konferensi pengabdian Masyarakat, 505-506.

Yuliana, I., \& Wijayanti, Y. (2019). Partisipasi Masyarakat Pada Program Bank Sampah. Higeia Journal Of Public Health Research And Development, 545555.

Undang-Undang RI No. 18, 2008, Pengelolaan Sampah. Jakarta

2010. Unilever Green and Clean "Bumi Kita". Yayasan Unilever Indonesia. Jakarta , 2010. Bank Sampah dan Program Lingkungan Yayasan Unilever. http// www.unilevergreenandclean.co.id/gr eenandclean. Yayasan Unilever Indonesia. Diakses pada tanggal 23 Januari 2012,

2011. Koperasi Bank Sampah, Solusi Permasalahan Sampah Yang Menguntungkan. http// www.unilevergreenandclean.co.id/gr eenandclean/banksampah. Yayasan Unilever Indonesia. 
PENAMAS ADI BUANA

Volume 3, Nomor 2, 01 Januari 2020
p-ISSN 2622-5727

e-ISSN 2622-5395 